BMJ Open Sport \& Exercise Medicine

\section{Biathlon Injury and Illness Surveillance project (BIIS): development of biathlon- specific surveillance forms in English, Russian, French and German}

To cite: Van Dyk C, Panagodage Perera $\mathrm{N}$, Carrabre JE, et al. Biathlon Injury and IIIness Surveillance project (BIIS): development of biathlon-specific surveillance forms in English, Russian, French and German. BMJ Open Sport \& Exercise Medicine 2019;5:e000588. doi:10.1136/ bmjsem-2019-000588

- Additional material is published online only. To view, please visit the journal online (http://dx.doi.org/10.1136/ bmjsem-2019-000588).

Accepted 20 October 2019
Check for updates

(C) Author(s) (or their employer(s)) 2019. Re-use permitted under CC BY-NC. No commercial re-use. See rights and permissions. Published by BMJ.

For numbered affiliations see end of article.

Correspondence to Assistant Professor Jane Fitzpatrick;

jane.fitzpatrick@unimelb.edu.au

\section{ABSTRACT}

Objective The aim of this project was to adapt the English, French, German and Russian versions of the International Olympic Committee (IOC) injury and illness surveillance form to be sport-specific for use in biathlon. Methods 23 medical representatives from 16 of the 55 biathlon federations participated in this project to adapt the form and create disease coding relevant to biathlon. The English version of the IOC injury and illness surveillance form was used as the primary template. Four review rounds were used to develop electronic fillable PDF forms. The changes were then forward translated onto the Russian, French and German forms.

Results Changes were made to event type to biathlonspecific events. A weekly reporting format was adopted in line with the race week format of World Cup events. Wherever possible, coding replaced free-text format to avoid translation issues. New codes were created to describe the time of injury/illness. A new symptom code was added to reflect the prevalence of respiratory infection: sore throat/cold symptoms. As the number of athletes in a team differs between weeks in the season, an additional question was added to ask for the 'number of athletes in the team for the week' and for the season. Conclusion This project provides a biathlon-specific injury and illness surveillance form in English, French, German and Russian. This forms the basis for surveillance that will contribute to a greater understanding of the illness and injury rate in elite biathletes and ultimately to enhanced athlete well-being and success in biathlon, and winter sports more generally.

\section{INTRODUCTION}

Exercise is well-known to provide a number of significant health benefits, particularly with regard to non-communicable diseases, such as cardiovascular disease, obesity, diabetes and some cancers, as well as reducing the risk of premature death, ${ }^{12}$ and these effects hold true for elite athletes. However, elite athletes do suffer from increased rates of musculoskeletal injury, both acute and chronic, as well as increased rates of illness, which detract from their performance. ${ }^{34}$

\section{What are the new findings?}

- This project outlines a process of utilising the validated International Olympic Committee injury and illness surveillance form to develop a sports-specific form for biathlon in English, French, German and Russian.

- By developing a sport-specific tool for measuring illness and injury rates among elite biathletes, this project forms the basis for phase 2 of the Biathlon Injury and IIIness Surveillance project, a longitudinal study of illness and injury rates in this cohort.

How will this impact injury and illness surveillance in sports?

This publication will act as a template for other sports looking to replicate this process.

- It provides injury and illness surveillance forms for use in prospective studies in the sport of biathlon.

- It encompasses all of the approved languages used by the sport of biathlon.

- It will allow for comparison of data collected at Olympics to be compared with injury and illness rates across World Cup seasons in the sport of biathlon.

The International Olympic Committee (IOC) has long regarded injury and illness surveillance as essential to athlete health given the long-term epidemiological data it provides. ${ }^{5}$ While there is good data pertaining to injury and illness rates across winter sports from the Vancouver, Sochi and PyeongChang Winter Olympic Games, ${ }^{6}$ to date, there are no longitudinal studies in any cross-country skiing or biathlon disciplines that reflect injury and illness rates across the season. Determining illness and injury rates forms the basis for providing effective healthcare to athletes, as well as helping to establish prevention measures, which are essential given the effect of injury and illness on athletic success. ${ }^{7}$ 
Biathlon is a popular Winter Olympic sport, and the International Biathlon Union (IBU) has 55 registered countries, details of which are available on the IBU website (https:// www. biathlonworld.com/about-ibu/member-federations/). Biathlon is an endurance sport that combines the aerobic demands of middle-distance cross-country skiing with the precision and calm of intermittent marksmanship. Given the endurance and skill requirements of the sport, there are significant training demands on biathletes at the elite level, which has previously been shown in other sports to increase the risk of overuse injury if these loads are not appropriately managed. ${ }^{89}$

To date, the only biathlon-specific data on injury and illness in the sport comes primarily from that collected at the Winter Olympic Games. During the 2010 Winter Olympics, 202 biathletes reported 1\% injuries and 11\% illnesses. ${ }^{10}$ Further, at the 2014 Winter Olympics, 204 biathletes reported $7 \%$ injuries and $10 \%$ illnesses, with $71 \%$ of the reported injuries occurred during training. ${ }^{6}$ In addition to data collected at Olympic Games, the IBU medical committee commissioned a cross-sectional survey in $2010^{9}$ to further establish injury rates. This data was retrospectively collected and is, thus, limited in its accuracy. It was found that $41 \%$ of 116 athletes reported at least one musculoskeletal injury during the previous year. ${ }^{9}$ Further, female biathletes sustained more injuries than males (55\% vs 40\%), findings which are consistent with a similar cohort of cross-country skiing athletes in a Norwegian study, where $50 \%$ of the female athletes reported sustaining a musculoskeletal injury. The injury incidence in the IBU study was 586 injuries per 1000 athletes per year, ${ }^{9}$ and the cross-sectional survey relied on athletes self-reports. Thus, the answers were biassed to each athletes' understanding or interpretation of the injury definition and their symptoms, and also subject to recall bias. Injury incidence during the 2014 Winter Olympics was 69 injuries per 1000 athletes. ${ }^{6}$ These injuries were recorded by the treating medical practitioner giving greater reliability of diagnosis, but are limited to the time period of the games. ${ }^{6}$ Thus, it is clear that the available evidence is limited and does not give any insight into the changing risk profiles throughout the year. Acute infective illness can adversely affect performance through a number of physiological changes, including impaired motor coordination and a decrease in muscle strength, ${ }^{11}$ as well as a reduction in VO2 max and subsequently endurance capacity, muscle wasting and changes in metabolic function. ${ }^{12}$ Evidence from other sports has shown that time lost to illness does affect athletes availability to train and compete, ${ }^{13}$ and data from a prospective cohort study show that runners who start an endurance race with systemic symptoms of an acute illness are 2-3 times less likely to complete the race. ${ }^{14}$

Additionally, it has been shown that illness rates increase with a longer duration of tournament, ${ }^{15}$ and that there are higher rates of illness in Winter Olympic Games ${ }^{6}$ when compared with Summer Olympic Games. ${ }^{16}$ Elite biathletes are, therefore, exposed to multiple risk factors for illness across a season given it is a Winter sport, with a season duration of 3 months that involves weekly international travel. ${ }^{1718}$ In recognition of this, the IBU medical committee has developed the Biathlon Injury and Illness Study (BIIS) to prospectively collect data on illness in addition to injury across two World Cup seasons in biathlon. The aim of phase 1 of the BIIS project was to develop a biathlon-specific surveillance form in English, French, German and Russian in line with the official languages of the sport of biathlon and recognising a large number of Russian-speaking Eastern European athletes involved in the sport.

\section{METHODS}

\section{Patient and public involvement}

All 55 medical teams from all biathlon federations were invited to attend a team physicians' seminar in Vienna in September 2017. Participants were recruited via IBU email communication with national federation team physicians and physiotherapists. Participation was restricted to team physicians and physiotherapists from biathlon national federations, which formed the basis of our inclusion criteria. Four review rounds were used in this project to adapt the IOC injury and illness surveillance form to a biathlon context. Figure 1 shows the development through rounds 1-4: Round 1 was held in conjunction with the IBU Team Physician Seminar where 23 medical representatives from 16 of the 55 biathlon federations ${ }^{19}$ attended the seminar and contributed to the initial development of the biathlon IOC injury and illness surveillance form. During this seminar, participants and the IBU medical committee were informed about the background and aims of the longitudinal Biathlon Injury and Illness Surveillance project. Adopting a similar practice familiar to other areas of healthcare science and medicine, ${ }^{20-22}$ the medical representatives from the biathlon federations were included to increase the relevance and the quality of the BIIS project and to secure buy-in from the biathlon federations to ensure the longevity of the BIIS project. Round 2 was conducted as a round table discussion of the suggestions from round 1 with all 23 medical representatives directly following the collation of results from round 1 . Round 3 was conducted by the IBU medical committee and research team members after adaptation of the form. Round 4 was conducted 6 weeks later by email with members of the medical representatives and the IBU administrative staff on the research team. The final adaptation was then translated into the three other languages.

\section{The questionnaire}

The IOC injury and illness surveillance form (online supplementary material 1) has been used in IOC injury surveillance projects, including the Winter Olympics, encompassing the sport of biathlon. ${ }^{6}{ }^{10}$ It records daily injury and illness data, including the athlete's accreditation number, sport and event, whether the injury or illness occurred in a round, heat or training, and the date and time of the injury or illness. Injuries are further coded by recording the injured body part, the type of the injury, the cause of the injury and the time lost in days. Illnesses are coded by affected systems, main symptoms 

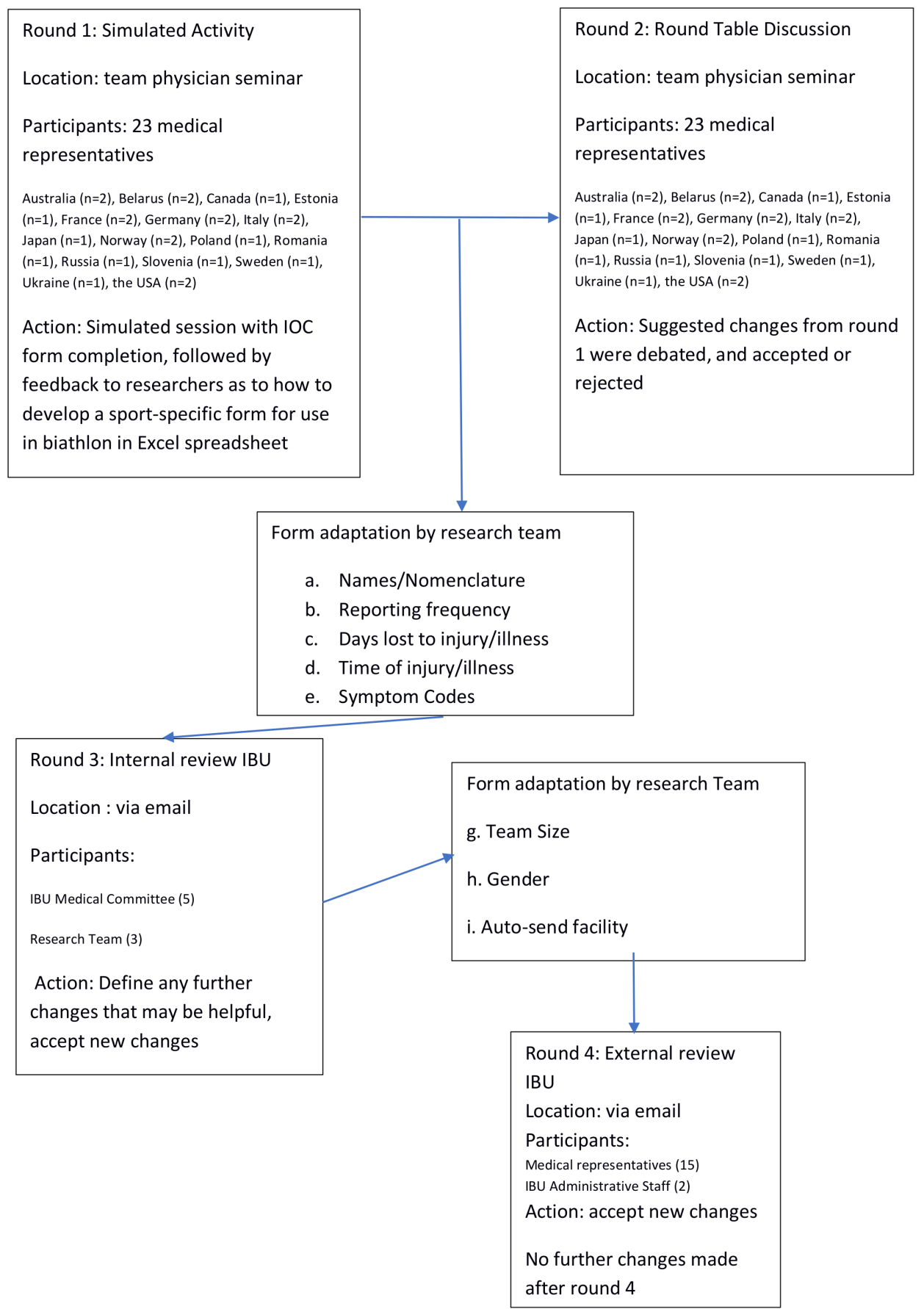

Figure 1 Development of the BIIS forms through rounds 1-4. BIIS, Biathlon Injury and IIIness Study; IBU, International Biathlon Union; IOC, International Olympic Committee.

and the cause of the illness. Anticipated time lost to both injury and illness is recorded in days. The IOC injury and illness surveillance form is available in English, French, German and Russian. Permission was obtained from the IOC medical and scientific committee to use the $I O C$ injury and illness surveillance form as a template for phase 1 of the BIIS project.

\section{Development of biathlon injury and illness surveillance form} In round 1, the English version of the IOC injury and illness surveillance form was used as the primary template. Native speakers used the forms in English, French, German or
Russian. Non-native speakers (whose first language was not represented) were encouraged to use the form in their strongest second language, for which English was the most common.

During the seminar, a simulated environment was created, and participants were asked to complete the IOC injury and illness surveillance form as they might do if this was the end of any regular World Cup week. The participants were requested to fill in the form based on the last injury sustained by any member of their team, to use as an example when completing the form in this simulated 
setting. Following this process, they recorded suggestions to improve the form, or to make it sport-specific. These suggestions were amalgamated to a spreadsheet during the course of the seminar.

Round 2 commenced once the suggestions had been recorded and collated as a round table discussion facilitated by JF and CVD, for each of the attendees to consider and discuss the feedback provided. Each comment or suggestion was discussed, and a consensus reached among participants as to whether the change should be included and in what form. Where this related to formal biathlon terms, such as the name of an event, for example, World Cup 3 Women's sprint, the official IBU nomenclature was used (eg, WC3, Sprint W). Immediately following the workshop, two researchers (CVD and JF) independently reviewed and rated the comments for each component of the IOC injury and illness surveillance form. If both researchers agreed, the participants had accepted the comments, changes were made to the wording or coding to reflect the review. If there was disagreement, then the comments were directed to two members of the IBU medical committee (JEC and FM) for a recommendation of subsequent changes. The collated changes were synthesised to develop the biathlon injury and illness surveillance form, then reviewed in round 3 by the IBU medical committee by email. The only change made at this time was the addition of a gender box, team size and an auto-submit feature, to allow this to be returned to the research team automatically online.

The final round 4 commenced 6 weeks after round 1. The collated biathlon injury and illness surveillance form was emailed to members of the medical representatives and the IBU administrative staff on the research team who were asked to repeat the same simulated exercise described in round 1. A simulated exercise was chosen as this process occurred outside of the World Cup season. Further, the participants were encouraged to report their experience using the biathlon injury and illness surveillance form and to accept/reject the changes to the form. The final version of the biathlon injury and illness surveillance form was proofed by the IBU medical committee and IBU office staff, circulated to attendees of the workshop and accepted. The final biathlon injury and illness surveillance form (online supplementary material 2 contains the English version) was translated into French, German and Russian as described in section Translation Biathlon injury and illness surveillance form.

\section{Translation biathlon injury and illness surveillance form}

Format changes to the biathlon injury and illness surveillance form, such as the addition of coding boxes, were made to the primary English document and copied to the French, German and Russian forms. Any changes to the text were highlighted in yellow and the English text copied onto the French, German and Russian forms. A bilingual member of the IBU office staff (French, German and Russian) was asked to forward translate the highlighted changes from English to French, German or Russian.
To evaluate the comprehensibility of the biathlon injury and illness surveillance form, two native speaking volunteer medical personnel who serve as team physicians gave feedback on corrections and/or suggestions. Then the highlighted areas were back-translated into English and checked for consistency with the original English version.

\section{RESULTS}

\section{Participants and changes to the forms}

About $30 \%(\mathrm{n}=16)$ of the 55 national federations that are part of the IBU contributed to the development of the biathlon injury and illness surveillance form. National federations from Australia $(n=2)$, Belarus $(n=2)$, Canada $(n=1)$, Estonia $(n=1)$, France $(n=2)$, Germany $(n=2)$, Italy $(n=2)$, Japan $(n=1)$, Norway $(n=2)$, Poland $(n=1)$, Romania $(n=1)$, Russia $(n=1)$, Slovenia $(n=1)$, Sweden $(n=1)$, Ukraine $(n=1)$ and the USA $(n=2)$ participated in this project.

The full set of changes made to the form in both stages is presented in table 1 .

In the first rounds 1 and 2, at the initial workshop, the following changes were discussed and recommended:

a. Simple changes to the names of organisations or event descriptions were clear and unanimously accepted. For example, 'Olympic Games' was changed to 'IBU', and event examples changed from other winter sports to biathlon-specific events. For example, 'Ice HockeyMen' was changed to 'WC3, Sprint W', the standard terminology for World Cup 3, Women's sprint.

b. Reporting frequency: The IOC injury and illness surveillance form was originally designed to be a daily report form. Workshop participants felt that filling in a weekly report was the best format for biathlon, given the competition structure and travel requirements of team physicians.

c. Days lost to injury or illness: In recognition of the four languages being used, a box was added to create a numeric code for the number of days lost to avoid having to read the numeric writing in different languages.

d. Time of injury/illness: A code box was created to better describe the time of the injury. The IOC injury and illness surveillance form asks for a written description, but it was felt that for biathlon this could be coded as 1 . If occurred in competition, 2. If occurred in training, 3 . If occurred in warm-up and 4. Other. It was agreed that this would accurately reflect the description of the times of injury/illness occurrence and avoid having to translate free text.

e. Symptom codes: The most significant change was to the main symptom codes. Regarding illness, the most common presentation perceived by the participants was a sore throat or cold symptoms. It was felt that the existing categories fever, pain, dyspnoea and cough did not accurately reflect the symptoms the participants would like to record. An additional code was added 'sore throat/cold symptoms' to reflect this.

The changes (a-e) were made to the form and sent for review in round 3 to the members of the IBU 
Table 1 Changes made to the IOC injury and illness surveillance form

\section{IOC injury and illness surveillance form}

Daily report

Olympic Games logo

NOC (national organising committee)

Olympic Games

Sport and event, for example, ice hockey (men)

Round, heat or training, for example, preliminary

\section{IBU injury and illness surveillance form}

Race report

IBU logo added

National federation

Number of athletes in the team for this week's report*

Number of athletes in your team for the whole season ${ }^{*}$

IBU events

Event, for example, WC3, Sprint W

Competition or training, for example, competition $A$ code box was added:

1. If occurred in competition*

2. If occurred in training*

3. If occurred in warm-up*

4. Other*

This was also changed in the explanatory code section.

\begin{tabular}{|c|c|}
\hline Absence in days & $\begin{array}{l}\text { A code box was added: } 0=0 \text { days, } 1=1 \text { day, } 2=2 \text { days, } 7=1 \text { week, } \\
14=2 \text { weeks, } 21=3 \text { weeks, } 28=4 \text { weeks, } 30=\text { more than } 4 \text { weeks, } \\
180=6 \text { months or more }\end{array}$ \\
\hline Illness: sport and event, for example, luge, single women & Event, for example, WC3, Sprint W \\
\hline $\begin{array}{l}\text { Under codes and classifications descriptions: } 2 \text {. Event, for } \\
\text { example, short track-Men's } 1500 \text { m, and so on }\end{array}$ & WC3, Sprint M; IBU Cup; Pursuit W \\
\hline 12 contact moving object, for example, puck & Eg puck deleted, nothing inserted \\
\hline \multirow[t]{2}{*}{ Main symptoms } & $\begin{array}{l}\text { Additional category added, labelled as follows: } 1 \text {. Sore throat/cold } \\
\text { symptoms }{ }^{*}\end{array}$ \\
\hline & Checkbox for gender, male/female, added \\
\hline
\end{tabular}

${ }^{*}$ Text requiring translation.

IBU, International Biathlon Union; IOC, International Olympic Committee; WC3, Sprint M, World Cup 3 Men's sprint; WC3, Sprint W, World Cup 3 Women's sprint.

medical committee and then in round 4 to the IBU staff and attendees of the workshop. The following changes (f-g) were recommended following the rounds 3 and 4 of review:

f. Team size: It was also felt that from a statistical perspective, it would be important to know not only the numerator, that is the number of athletes presenting with a specific injury or illness, but also the denominator, that is, the number of athletes in the team. As the number of athletes in a team differs between weeks in the season, an additional question was added to ask for the 'number of athletes in the team for the week' and for the season.

g. Checkbox for male and female was added.

\section{Translation process}

Forward/back translation: As regards with text translation changes, only the specific changes to the text were translated rather than the entire form and there were very few areas requiring translation.

The key phrases to be translated were:

a. Number of athletes in the team for this week's report and number of athletes in your team for the whole season.

\section{b. 1. If occurred in competition, 2. If occurred in training, 3. If occurred in warm-up and 4. Other. \\ c. Sore throat/cold symptoms.}

\section{Form of data collection}

The writeable PDF format was determined by the workshop participants as the preferred reporting format, as it is both digital and easy to use. This is especially important given the structure of the biathlon season, whereby teams move from country to country each week for each event on the World Cup calendar. It was agreed in the workshop that form submission would be best done electronically on a Monday after the competition, which is the team travel day. Given the movement of teams, an electronic document was favoured by the workshop participants and researchers.

The data is saved and protected so that it cannot be changed and can be referred back to if there is a need to re-check data. In recognition of the privacy of athletes, athlete accreditation numbers will first be linked to a unique ID code in the system for the athlete at the start of the season. The ID codes will not be sequential or numeric. If the data entry has been incorrectly transcribed via the accreditation number, there will not be a 'corresponding unique ID' and the data entry error can be identified. 


\section{DISCUSSION}

This project has developed a biathlon sport-specific injury and illness surveillance form in the four most commonly used languages in biathlon. It is important to have a sport-specific form for injury and illness surveillance in sports. It is also important to have an available translation of these forms to enable appropriate data collection in a non-English-speaking population. The IOC injury and illness surveillance forms have been validated $^{61023}$ and allow capture of data across multisport platforms, particularly Olympic Games. This study is the first of its kind in adapting the validated IOC injury and illness surveillance forms to a sport-specific version. It retains the coding system used in IOC surveillance projects previously so that data collected utilising these new sport-specific forms can be compared with data collected at Winter Olympics and other multisport events.

The process involved significant consultation with the IBU medical committee and team physicians, who are all actively engaged in the sport. This ensures the relevance and quality of the BIIS project and will help to secure buy-in from the biathlon federations to ensure the longevity of the future data collection phases of the BIIS project. While only $30 \%$ of biathlon nations were represented, there were representatives from both Central and Eastern Europe, Russia, the Asia-Pacific region and North America. With eight of the top ten biathlon nations represented, the participants reflect the views of the major nations and all parts of the world (https://www.statista.com/statistics/802123/medaltable-country-winter-olympics-biathlon/). In addition, there were native speakers from all the four languages within the group.

Only minimal changes were made to the IOC injury and illness surveillance form when creating the biathlon injury and illness surveillance forms. The IOC injury and illness surveillance form is validated and data can be compared with data collected using the biathlon injury and illness surveillance forms. This also applies to the translation process as only the minimal text changes were translated, retaining the validity of the translated form.

The limitations of this study are having the forms available in only four languages. As the sport grows, particularly in the Asia-Pacific region, there may be a need to consider forms in additional languages. There are limitations relating to the use of a PDF form as the data has to be transferred to a spreadsheet. This limitation has been accepted to protect athlete privacy as there will be no access to athlete identification in the data spreadsheets, which would automatically occur if the data went directly to a spreadsheet format.

The benefit of this project to all winter sport is significant given the unique challenges of sports participation in an alpine environment and current lack of evidence regarding injury and illness surveillance in this setting. This process can be replicated by other sports, enabling a better understanding of the impact of injury and illness in different sports.

\section{CONCLUSION}

This project has developed a biathlon sport-specific injury and illness surveillance form in the four most commonly used languages in biathlon: English, French, German and Russian. This form will allow data collection over the next 5-10 years which will contribute to the development of an injury and illness database for the sport of biathlon. This has far-reaching implications for both biathlon and winter sports more generally, and will form the basis for the implementation of preventative measures that will ultimately contribute to enhance athlete well-being and success.

\section{Author affiliations}

${ }^{1}$ Research, Australasian College of Sport and Exercise Physicians (ACSEP), Melbourne, Victoria, Australia

${ }^{2}$ Nuffield Department of Orthopaedics, University of Oxford, Oxford, United Kingdom ${ }^{3}$ Centre for Sport, Exercise and Osteoarthritis Research Versus Arthritis, University of Oxford, Oxford, United Kingdom

${ }^{4}$ Division of Physiotherapy, Department of Medical and Health Sciences, Linköping University, Linköping, Sweden

${ }^{5}$ School of Allied Health, Human Services and Sport, Latrobe University, Melbourne, Victoria, Australia

${ }^{6}$ Family Practice, Mayo Clinic, Waconia, Minnesota, USA

${ }^{7}$ Lakeview Clinic, Watertown, Minnesota, USA

${ }^{8}$ Department of Biomedical and Surgical Specialties Sciences, The University of Ferrara, Ferrara, Italy

${ }^{9}$ School of Health Science, Faculty of Medicine, Dentistry and Health Sciences, The University of Melbourne, Victoria, Australia

${ }^{10}$ Sports Medicine Professionals Pty Ltd, Richmond, Victoria, Australia

Twitter Carlee Van Dyk @TheCVDfiles, Nirmala Panagodage Perera @Nim_Perera and Jane Fitzpatrick @sportsdocaus

Acknowledgements The authors wish to particularly thank the representatives from national federations who were involved in the Team Physicians Seminar and this project: BLR Pavel Drinevskiy, BLR Iryna Rybina, EST Taivo Väärsi, France Pierre Jeanier, France Laurent Schmitt, GER Jan und Katja Wüstenfeld, GER Jürgen Klaus Marquardt, ITA Anna-Maria Malagoni, JPN Tomohito Imai, NOR Baart Freberg, NOR Ola Berger, POL Andrii Tymchenko, RUS Sergey Kostin, SLO Matej Svetec, ROU Valeriu Tomescu, SWE Lykke Tamm, UKR Oleksii Pisarenko, the USA Brett Toresdah and the USA Marci Goolsby.

Contributors CVD, JEC, FM and JF contributed to the study design, and data collection and analysis. CVD wrote the first draft. All the authors made substantial contributions to the conception or design of the work, or the acquisition, analysis or interpretation of data, drafting the work or revising it critically for important intellectual content. All the authors gave final approval of the version published. The authors agree to be accountable for all aspects of the work in ensuring that questions related to the accuracy or integrity of any part of the work are appropriately investigated and resolved.

Funding Funding for this project was provided by the International Biathlon Union. Competing interests None declared.

Patient consent for publication Not required.

Ethics approval This project has been approved by the Bellberry Human Research Ethics Committee (project number 2017-01-057).

Provenance and peer review Not commissioned; externally peer reviewed.

Data availability statement All data relevant to the study are included in the article or uploaded as supplementary information.

Open access This is an open access article distributed in accordance with the Creative Commons Attribution Non Commercial (CC BY-NC 4.0) license, which permits others to distribute, remix, adapt, build upon this work non-commercially, 
and license their derivative works on different terms, provided the original work is properly cited, appropriate credit is given, any changes made indicated, and the use is non-commercial. See: http://creativecommons.org/licenses/by-nc/4.0/.

\section{ORCID iDs}

Carlee Van Dyk https://orcid.org/0000-0002-1714-134X

Nirmala Panagodage Perera http://orcid.org/0000-0001-6110-8945

Fabio Manfredini https://orcid.org/0000-0001-9476-6434

Jane Fitzpatrick http://orcid.org/0000-0002-9578-026X

\section{REFERENCES}

1 Global recommendations on physical activity for health. Available: https://www.who.int/dietphysicalactivity/publications/ 9789241599979/en/ [Accessed 29 Sep 2019]

2 Physical activity and health - the benefits of physical activity. Available: http://wwwcdc gov/. http://www.cdc.gov/physicalactivity/ everyone/health/index.html [Accessed 29 Sep 2019].

3 Drawer S, Fuller CW. Propensity for osteoarthritis and lower limb joint pain in retired professional soccer players. Br J Sports Med 2001;35:402-8.

4 Drew MK, Raysmith BP, Charlton PC. Injuries impair the chance of successful performance by sportspeople: a systematic review. $\mathrm{Br} \mathrm{J}$ Sports Med 2017;51:1209-14.

5 Junge A, Engebretsen L, Alonso JM, et al. Injury surveillance in multi-sport events: the International Olympic Committee approach. Br J Sports Med 2008;42:413-21.

6 Soligard T, Steffen K, Palmer-Green D, et al. Sports injuries and illnesses in the Sochi 2014 Olympic winter games. Br J Sports Med 2015;49:441-7.

7 Drawer S, Fuller CW. Evaluating the level of injury in English professional football using a risk based assessment process. $\mathrm{Br} \mathrm{J}$ Sports Med 2002;36:446-51.

8 Gabbett TJ. The training-injury prevention paradox: should athletes be training smarter and harder? Br J Sports Med 2016;50:273-80.

9 Blut D, Santer S, Carrabre J, et al. Epidemiology of musculoskeletal injuries among elite biathletes: a preliminary study. Clin J Sport Med 2010;20:322-4.

10 Engebretsen L, Steffen K, Alonso JM, et al. Sports injuries and illnesses during the winter Olympic Games 2010. Br J Sports Med 2010;44:772-80.
11 Weidner TG, Sevier TL. Sport, exercise, and the common cold. $J$ Athl Train 1996;31:154-9.

12 Friman G, Wesslén L. Special feature for the Olympics: effects of exercise on the immune system: infections and exercise in highperformance athletes. Immunol Cell Biol 2000;78:510-22.

13 Raysmith BP, Drew MK. Performance success or failure is influenced by weeks lost to injury and illness in elite Australian track and field athletes: a 5-year prospective study. J Sci Med Sport 2016;19:778-83.

14 Van Tonder A, Schwellnus M, Swanevelder S, et al. A prospective cohort study of 7031 distance runners shows that 1 in 13 report systemic symptoms of an acute illness in the 8-12 day period before a race, increasing their risk of not finishing the race 1.9 times for those runners who started the race: SAFER study IV. Br J Sports Med 2016;50:939-45.

15 Schwellnus M, Derman W, Page T, et al. Illness during the 2010 Super 14 Rugby Union tournament - a prospective study involving 22676 player days. Br J Sports Med 2012;46:499-504.

16 Engebretsen L, Soligard T, Steffen K, et al. Sports injuries and illnesses during the London summer Olympic Games 2012. Br J Sports Med 2013;47:407-14.

17 Schwellnus MP, Derman WE, Jordaan E, et al. Elite athletes travelling to international destinations $>5$ time zone differences from their home country have a 2-3-fold increased risk of illness. Br J Sports Med 2012;46:816-21.

18 Svendsen IS, Taylor IM, Tønnessen E, et al. Training-related and competition-related risk factors for respiratory tract and gastrointestinal infections in elite cross-country skiers. $\mathrm{Br} J$ Sports Med 2016;50:809-15.

19 Member federations. Available: https://www.biathlonworld.com/ about-ibu/member-federations/ [Accessed 23 Mar 2019].

20 Brett J, Staniszewska S, Mockford C, et al. A systematic review of the impact of patient and public involvement on service users, researchers and communities. Patient 2014:7:387-95.

21 Brett J, Staniszewska S, Mockford C, et al. Mapping the impact of patient and public involvement on health and social care research: a systematic review. Health Expect 2014;17:637-50.

22 Staley K. 'Is it worth doing?' measuring the impact of patient and public involvement in research. Res Involv Engagem 2015;1.

23 Steffen K, Moseid CH, Engebretsen L, et al. Sports injuries and illnesses in the Lillehammer 2016 youth Olympic winter games. $\mathrm{Br} \mathrm{J}$ Sports Med 2016;51:1-8. 